\title{
Polyunsaturated fatty acids, thrombosis and vascular disease
}

\author{
Giovanni Di Minno, Antonella Tufano, Tiziana Garofano, Matteo Nicola Dario Di Minno \\ Clinica Medica, Dipartimento di Medicina Clinica e Sperimentale, Universita' degli Studi di Napoli "Federico II", Italy
}

\begin{abstract}
In the 80's, retrospective studies showed an inverse relation between fish consumption and ischemic heart disease (IHD) mortality. In parallel, fish fats containing the polyunsaturated fatty acid (PUFA) eicosapentaenoic (EPA) were shown to impair platelet aggregation and thromboxane formation. The results of the large prospective trials, the Diet and Reinfarction Trial (DART) and the Lyon Heart Study in the secondary prevention of myocardial infarction, have further supported the interrelationships between diet and dietary prevention of IHD. In the DART Study, the cardioprotection by EPA was paralleled by an increase plasma content of EPA. In the Lyon, in addition to changes in the content of EPA, changes in other well known variables (i.e. leukocytes and vitamin $\mathrm{E}$ ), often abnormal in subjects prone to arterial thrombosis, have been found. The GISSI Prevenzione Trial was a prospective, multicentric, open labeled trial with a factorial design, in which 11,324 recent $(<3 \mathrm{mo}$ ) survivors of a first myocardial infarction were assigned to receive, in addition to the usual strategy, a supplementation of $n-3$ PUFA, vitamin $E$, or the combination of the two. Cardiovascular death $(-30 \%)$, coronary heart disease death $(-35 \%)$, total death $(-20 \%)$ and sudden death $(-45 \%)$ were all significantly reduced by the n-3 PUFA supplementation. The reduced tenden-
\end{abstract}

(c) 2002 S. Karger AG. Basel

$1424-8832 / 02 / 0326-0361 \$ 18.50 / 0$

Fax +4161306 1234 cy to sudden death of survivors of myocardial infarction on treatment with n-3 PUFA are in keeping with a series of scanty but reliable clinical data as well as of experimental studies. However, we believe that large-scale prospective multicentric randomized trials aimed at preventing sudden death in high-risk patients as well as at testing the effects of $n-3$ PUFA in patients with intracoronary devices and sustained ventricular arrhythmias, are a major direction to be followed to better understand the n-3 PUFA and sudden death issue.

Copyright (C) 2002 S. Karger AG. Basel

\section{Introduction}

In the early '60s and '70s, dietary advice to prevent recurrence of myocardial ischemia was inconclusive [1-5]. This was likely to be due to the small $(\sim 500)$ number of subjects examined. Moreover, in these studies, attempts to lower plasma cholesterol levels in survivors of myocardial infarction (MI) were based on diets low in fat or with high polyunsaturated/saturated ratios. In view of this, the intake of saturated fats was decreased and that of unsaturated fats increased [1-5]. Thus, the study design and the sample size may have been inadequate to address the issue.

In the 80 's, three retrospective studies showed an inverse relation between fish consumption and ischemic heart disease (IHD) mortality [6-8]. In parallel, fish fats containing the 
polyunsaturated fatty acid eicosapentaenoic (EPA) were shown to impair platelet aggregation and thromboxane formation, two major events in arterial thrombosis [9]. This was due to the fact that EPA can replace arachidonic acid in platelet membrane phospholipids, giving rise to prostaglandins and thromboxanes of the 3 series, with a very limited pro-aggregatory and vasocostrictive activity. The combined data have fostered the search for further interrelationships between nutrition and thrombogenic factors.

The results of the large prospective Diet and Reinfarction (DART) Study in the secondary prevention of MI, [11] have supported the possibility of a nutritional prevention of ischemic heart disease.

\section{The DART study}

In this prospective, randomised, controlled trial with a factorial design, 2,033 male survivors of MI aged $<70$ yrs were enlisted [11]. Primary endpoints of the study were total mortality and ischemic heart disease events (i.e. ischemic deaths plus non-fatal MI). After being adviced to stop smoking and/or encouraged not to relapse, all subjects were randomly allocated to groups to receive (or not) advice on (each of) three dietary factors (see below), randomization for each factor being independent of the other two. Advice on fat consisted in decreasing fat intake to $30 \%$ of total energy and increasing polyunsaturated/saturated ratio to 1.0; advice on fish consisted in instructing the subjects to eat at least two weekly portions (200-400 g) of fatty fish (mackarel, herring, kipper, salmon, trout, sardine). Subjects who did not tolerate fish were instructed to ingest $0.5 \mathrm{~g}$ of Maxepa. Fiber advice consisted in increasing cereal fibre intake to $18 \mathrm{~g} / \mathrm{d}$. All subjects were evaluated a 6 months and 2 years after entering the trial. While no major beneficial effect emerged with respect to fat or fibre advice, relevant results were observed in survivors who were advised to eat fish, all deaths and IHD deaths in the later group being $9.3 \%$ and $7.7 \%$ respectively, vs $12.8 \%$ and $11.4 \%$ in subjects that did not receive fish advice $(\mathrm{p}<0.05$ and 0.01 respectively, $\log$ rank test). In keeping with the lowering of all deaths and ischemic deaths, in a subgroup of subjects plasma where EPA was measured, this fatty acid was $0.59 \%$ of total in subjects that received a fish advice and $0.46 \%$ in plasma of those that did not receive any fish advice $(\mathrm{p}<0.01)$. When life table survival curves were analyzed, the difference in favour of fish advice was found to occur as early as in the first 3 months of treatment, and to persist for up to two years. During this time period, a $29 \%$ reduction of mortality was observed. Since no major effects was observed on plasma levels of cholesterol or its fractions during the study period, the data were thought to support the ability of diets enriched in EPA to lower ischemic complications of atherosclerosis. This possibility was further explored [12].

\section{The Lyon Heart study}

This was a prospective, randomized single-blinded multicentric trial whose primary endpoints were death and non-fatal infarction [12]. Of the 605 survivors enlisted, 303 adopted a prudential diet and 302 adopted a Mediterranean-type of diet, with more bread, vegetables, fish, fresh fruit and olive oil (or margarine enriched in alpha-linolenic acid for subjects who did not like olive oil). Primary end-points were cardiovascular (CV) death and non-fatal acute MI. The subjects were evaluated every year for 5 years, starting 6 months after the ischemic event. At the 4-year follow-up, there were $19 \mathrm{CV}$ deaths in the control group $(1.3 \%)$ and 6 in the experimental one $(0.41 \%$, $\mathrm{p}<0.01)$. All primary end-points were $44(4.07 \%)$ in the control group and 14 (1.245) in the experimental group, $\mathrm{p}<0.0001$. While no major effect was found on non-fatal myocardial infarctions and non-cardiovascular mortality, the overall mortality was 24 in the control group (1.74\%) and 14 in the experimental group $(0.95 \%, \mathrm{p}=0.03)$.

Similar to the DART study, the beneficial effect of this diet occurred early after randomization and was not associated with changes in plasma cholesterol or HDL-cholesterol levels. After correction for other factors, a surprisingly high (76\%) reduction in the risk of cardiac death was found during the observation period. The protective effect of the experimental diet was associated with enhanced plasma levels of EPA $(0.7 \%$ vs $1 \%, \mathrm{p}<0.005)$ and of its parent fatty acid, alpha-linolenic acid $(0.3 \%$ vs $0.6 \%, \mathrm{p}<0.001)$. In keeping with this, arachidonic acid (the parent fatty acid of prostaglandins and thromboxanes of the 2 series, with potent pro-aggregating and vasocostrictive effects), was significantly reduced in subjects who had received the experimental diet. However, other variables were affected by the Mediterranean-type of diet (experimental) as well. The potent antioxidant vitamines $\mathrm{E}$ and $\mathrm{C}$, were significantly increased while granulocyte counts (a predisposing condition to myocardial re-infarction) $[13,14]$ were lowered (p always $<0.005$ ).

\section{GISSI Prevenzione Trial}

Vis-à-vis the clinical effectiveness of this strategy, some open issues were envisaged:1) The higher protection found in the Lyon Heart Study, as compared to the DART Study, could be either the result of the smaller sample size or the consequence of the combination of n-3 PUFA with a Mediterraneantype of diet in the Lyon Study; 2) In spite of the effectiveness, the amount of fish consumed by the patients in the DART and in the Lyon Study varied dramatically. This argued for a nutriceutical able to provide comparable amounts of n-3 PUFA; 3) Some data supported the notion that the effect of n3 PUFA was related to their ability to lower the byosintesis of prostaglandins of the 2 series (with marked pro-aggregatory 
and vasocostrictive activities). Aspirin is able to achieve a stronger inhibition of the prostaglandins of the 2 series. In view of this, and in view of the fact that from the 80's aspirin was routinely used in post-MI patients, the need for alternative mechanisms of action of n-3 PUFA were mandatory. In reality (table) data supporting the latter formulation were already available in the literature. These concepts were the background for the design of the GISSI prevenzione Trial.

This is a prospective, multicentric, open labeled trial with a factorial design, in which 11,324 recent $(<3 \mathrm{mo})$ survivors of a first MI aged 50-80 years, were randomly assigned to receive, in addition to the usual GISSI strategy (aspirin, beta-blockers, nitrate, ACE-I, statins), a supplementation of n-3 PUFA (1 g/d corresponding to $850 \mathrm{mg}$ of a mixture of EPA+ docosahexaenoic acid [DHA] in a 1:1.4 ratio), vitamin $E(300 \mathrm{mg} / \mathrm{d})$, or the combination of n-3 PUFA + Vitamin E [15]. The clinical assessment and food questionnaires were obtained at 6 months $[6,12,18,30]$ and 42. Primary end-points were all cause death, CV death, non-fatal MI and stroke. While the treatment with vitamin $\mathrm{E}$ was not effective as to event-free survival $(293 / 2828$ in controls vs $252 / 2830, p=0.07)$, the treatment with n-3 PUFA significantly reduced the risk of cardiovascular disease $(293 / 2828$ vs $236 / 2836,10.4 \%$ two-way analysis, $15 \%$ four-way analysis, $\mathrm{p}=0.009)$. The effect of the combination of PUFA+ vitamin E (293/2828 vs 236/2830, $\mathrm{p}=0.01$ ) was comparable to the $\mathrm{n}-3$ PUFA supplementation alone. When the data were stratified as to individual endpoints, cardiovascular death $(-30 \%)$, coronary heart disease death $(-35 \%)$, total death $(-20 \%)$ and sudden death $(-45 \%)$ were all significantly reduced by the n-3 PUFA supplementation. The $45 \%$ reduction in sudden death was not associated with changes in the use of drugs (e.g. antiplatelet agents, betablockers, ACE-I or cholesterol-lowering agents) that may play a role in lowering the number of complex arrhythmias, thus the underlying mechanism remains elusive.

\section{n-3 PUFA and prevention of sudden death}

The data obtained from the GISSI Prevenzione study have fostered the search for mechanisms explaining the reduced tendency to sudden death of survivors of a MI on treatment with n-3 PUFA. From an epidemiological point of view, in 79 patients with complex arrhythmias, PUFA administration reduced the number of premature ventricular beats [16]; in 52 survivors of acute MI with left ventricular dysfunction, an at least once a week fish consumption was associated with marked effects on heart rate variability; [17] and, in the Physicians' Health study, there was a strong inverse correlation between fish consumption and sudden death as well as total mortality [18, 19]. More recently, in the Nurses Health Study (NHS), the authors observed a $30 \%$ reduction in the risk of major coronary events in women treated with n-3 supplemen- tation. This reduction increased when the authors considered only fatal events (coronary deaths) [10].

An antiarrhytmic/antifibrillatory effect of EPA is documented $[20,21]$. Several Authors have reported a variety of potential mechanisms of n-3 PUFA (table) that may be relevant to their antithrombotic potential. In 14 healthy volunteers, a one-mo supplementation of a preparation of EPA and DHA superimposable to that employed in the GISSI Prevenzione study, caused, in parallel with increases in the plasma and platelet content of EPA and DHA, an impaired aggregation of platelets in response to collagen or ADP, that correlated ( $\mathrm{p}=0.036$ and 0.068 respectively) to changes in the intracellular $\mathrm{pH}(\mathrm{pHi})$ of the $\mathrm{Na}+\mathrm{H}+$ reverse transport [22]. In addition to platelet function, the latter mechanism is important as to lymphocyte function and blood pressure control [23, 24] The impaired aggregation was independent of thromboxane biosynthesis, in that study.

An additional explanation to elucidate the reduction of sudden death in the GISSI Prevenzione Study involves the fact that $>80 \%$ of individuals were simultaneously receiving aspirin and of n-3 PUFA. Since aspirin impairs thromboxane formation, a major mechanism of platelet activation and n-3 PUFA impair ADP-induced aggregation, another important mechanism of platelet activation, sudden death prevention may well be the result of a more intensive anti-platelet treatment. Studies in other settings (CABG, coronary stenting etc) where the combination of antiplatelet agents greatly reduced coronary deaths support this formulation.

\section{Perspectives}

Antiarrhythmic effects in dogs and rats; the scanty but favourable data on the antiarrhytmic effects in humans; the total plus sudden death reduction in randomized trials on PUFA in post MI individuals and, finally, the indirect correlation between fish consumption and sudden death in total mortality reduction, suggest that the antiarrythmic/antifibrillatory hypotesis is a major direction to understand the interrelationships between n-3 PUFA and sudden death prevention. In this respect we believe that large-scale prospective multicentric randomized trials aimed at preventing sudden death in highrisk patients (CHF, post-AMI, with LV disfunction) as well as at testng the effects of n-3 PUFA in patients with intra-coronary devices and sustained ventricular arrhythmias, are urgently needed.

From polygenic disorders, we have learned that by lowering the threshold and becoming a susceptibility gene, a polymorphism can lead to a given effect if it is present in the appropriate milieu [25]. This implies that, within the study populations, a careful definition of the genetic backgroung of the sample, of intermediate phenotypes; of the hormonal status, of drug treatment and of the stage(s) in atherothrombosis is 
important for a reliable search for the antiarrhythmic/antifibrillatory effect of n-3 PUFA and, more in general, for a better understanding of the n-3 PUFA and sudden death issue.

\section{References}

TABLE

N-3 Fatty acids and CHD potential antithrombotic mechanisms

\begin{tabular}{lcl}
\hline Variable & Effect & Author (year) \\
\hline Plasma triglycerides & $\downarrow$ & Sanders (1985) \\
VLDL- cholesterol & $\downarrow$ & Nestel (1984) \\
LDL- cholesterol & $\downarrow$ & Subbaiah (1989) \\
HDL- cholesterol & $\uparrow$ & Sanders (1986) \\
Membrane fluidity & $\uparrow$ & Torano (1983) \\
Monocyte adhesion (EC) & $\downarrow$ & Kim (1990) \\
IL-1 and TNF-cc (mono) & $\downarrow$ & Enders (1989) \\
PDGF (EC) & $\downarrow$ & Fox (1989) \\
PDGF (pts) & $\downarrow$ & Smith (1989) \\
Plasma fibrinogen & $\downarrow$ & Schmidt (1990) \\
PG and TX synthesis & $\downarrow$ & Godnight (1990) \\
Vascular PGI2 & $\uparrow$ & De Caterina (1990) \\
LTB4 (neutr) & $\downarrow$ & Lee (1985) \\
LTB4(mono) & $\downarrow$ & Lokesh(1988) \\
EDGF release (arteries) & $\uparrow$ & Shinokawa (1989) \\
\hline
\end{tabular}

$\uparrow$ : enhance $\downarrow$ : lower

1. Leren P. The Oslo Diet-Heart Study. Eleven year report. Circulation 1970

42:39-46.

2. Morris JN, Ball KP, Antonis A, Brigden WW, Burns-Cox CJ, Fulton M, Haigh M, Hall GJL, Hanington E, Heady JA, McAllen PM, Pilkington TRE, Royston GR, Sharland DE, Sowry GSC, Wilson C. Controlled trial of soya-bean oil in myocardial infarction. Lancet 1968 II:694-700.

3. Woodhill JM, Palmer AJ, Leelarthaepin B, McGilchrist C, Blacket RB. Low fat, low cholesterol in secondary prevention of coronary heart disease. Adv Exper Med Biol 1978 209:317-31.

4. Research Committee. Low-fat diet in myocardial infarction: a controlled trial. Lancet 1965 II:501-4.

5. Rose GA, Thompson WB, Williams RT. Corn oil in treatment of ischemic heart disease. $\mathrm{Br}$ Med J 1965 I:1531-33.

6. Kromhout D, Bosschieter EB, Coulander CdeL . The inverse relation between fish consumption and 20-year mortality from coronary heart disease. N Engl J Med 1985 312:120509.

7. Shekelle RB, Missell LV, Oglesby P, Shryock AM, Stamler J. Fish consumption and mortality from coronary heart disease. $\mathrm{Br}$ Med J 1985 313:820.

8. Norell SE, Ahloom A Feychting M, Pedersen NL. Fish consumption and mortality from coronary heart disease. Br Med J 1986 293:426.

9. Dyerberg J, Bang HO, Stoffersen E, Moncada S, Vane JR. Eicosapentaenoic acid and prevention of thrombosis and atherosclerosis? Lancet 1978 II; 117-19.

10. Hu FB, Bronner L, Willett WC, et al. Fish and omega- 3 fatty acids intake and risk of coronary heart disease in women. $\mathbf{J}$ Am Med
Assoc; 2002 287: 1815-21.

11. Burr ML, Gilbert JF, Holliday RM, Elwood PC, Fenily AM, Rogers S, Sweetnam PM, Deadman NM. Effects of changes in fat, fish, and fiber intakes on death and myocardial infarction : diet and myocardial infarction (DART). Lancet 1989 II:757-61.

12. de Lorgeril M, Renaud S, Mamelle N, Salen P, Martin JL, Monjaud I, Guidollet J, Touboul P Delaye J. Mediterranean alpha-linolenic acidrich diet in secondary prevention of coronary heart disease. Lancet 1994 343:1454-59.

13. Ernst E, Hammerschmidt DE, Bagge U, Matrai A, Dermandy JA. Leukocytes and the risk of ischemic disease. JAMA 1987 257:2318-2324.

14. Danesh J, Collins R, Appleby P, Peto R.Association of fibrinogen, c-reactive protein, albumin, or leukocyte count with coronary heart disease. meta-analyses of prospective studies. JAMA 1998 279:1477-1482.

15. Gruppo Italiano per lo studio della Sopravvivenza nell'Infarto miocardico. Dietary supplementation with n-3 polyunsaturated fatty acids and vitamin in myocardia infarction: results of the GISSI-Prevenzione trial. Lancet 1999 354: 447-455.

16. Sellmayer A, Witzgall $\mathrm{H}$, lorenz RL, Weber PC. Effects of dietary fish oil on ventricular premature complexes. Am. J. Cardiol 1995 76: 974-977.

17. Christensen JH, Korup E, Aaroe J, Toft E, Moller J, Rasmussen K, Dyeberg J, Schmidt EB. Fish consumption, n-3 fatty acids in cell membranes, and heart rate variations in survivors of myocardial infarction with left ventricular dysfunction. Am. J. Cardiol 1997 79: 1670-1673.

18. Albert CM, Hennekens CH, O’Donnell CJ,
Ajani UA, Carey VJ, Willet WC, Ruskin JN, Manson JE. Fish consumption and risk of sudden cardiac death. JAMA 1998 279: 23-28.

19. Albert CM, Campos H, Meir J, et al. Blood levels of long-chain n-3 fatty acids and the risk of sudden death. New Engl J Med; 2002 346: 1113-1118.

20. Kang JX, Leaf A. Prevention of fatal cardiac arrhythmias by polyunsaturated fatty acids. Am J clin Nutr 71(1 Suppl): 2000 202S-207S.

21. Xiao YF, Ke Q, Wang SY, Auktor K, Yang Y, Wang GK, Morgan JP, Leaf A. Single point mutations affect fatty acid block of human myocardial sodium channel alpha subunit $\mathrm{Na}+$ channels. Proc Natl Acad Sci USA 2001 98(6): 3606-3611.

22. Cerbone AM, Cirillo F, Coppola a, Rise $\mathrm{P}$, Stragliotto E, Galli C, Giordano M, tremoli E, Di Minno G.) Persistent impairment of platelet aggregation following cessation of a shortcourse dietary supplementation of moderate amounts of n-3 fatty acid ethyl esters. Thromb Haemost 1999 82(1): 128-133.

23. Gaidiano G, Ghigo D, Schena M, Bergui L, treves S, Turrini F, Cappio FC, Bosia A. $\mathrm{Na}+\mathrm{K}+$ exchange activation mediates the lipopolysaccharide-induced proliferation of human lymphocytes and is impaired in malignant B-chronic lymphocytic leukemia lymphocyte. J Immunol 1989 142: 913-918.

24. Resnik LM, Gupta RK, Sosa RE, Corbett LM, Laragh $\mathrm{JH}$. Intracellular $\mathrm{pH}$ in human and experimental hypertension. proc Natl Acad Sci USA 1987 84: 7663-7667.

25. Di Minno G, Grandone E and Margaglione M. Clinical relevance of polymorphic markers of arterial thrombosis. Thromb Haemost 1997 78(1):462-466 